\title{
Deutsch-Spanische Handelskorrespondenz
}

Nach der Methode von Prof. Th. de Beaux

bearbeitet von

\section{Dr. Alfredo Nadal de Mariezcurrena}

LEIPZIG

G. J. Göschen'sche Verlagshandlung 
Alle Rechte von der Verlagshandlung vorbehalten

Spamersche Buchdruckerei in Leipzig 


\title{
Inhaltsverzeichnis. Indice.
}

\begin{abstract}
Allgemeines. Generalidades.
Aufschrift der Postsendungen; Form der Handelsbriefe; Begrüßungs- und Schlußformeln; Schreibung des Datums; Gebrauch der Zeiten: Umschreibung deutscher Um. standswörter . . . . . . . Seite ?

Dirección de los envios postales; Forma de la correspondencia mercantil; Encabezamiento y conclusión de los escritos; Fecha; Uso cortés de los tiempos verbales; Locuciones más frecuentes . . Pág. 7
\end{abstract}

\section{Erläuterungen zum Warengeschäft.}

a) Anfragen, Bitte um Preisanstellung; b) Anträge, Auerbieten, Preisanstellung, Offerten; c) Bestellungen, Aufträge, Orders; d) Ausfübrungs- und Versandanzeigen, Rechnungen; e) Begleichung der Rechnung, Zahlung, Anschaffung, Regulierung: f) Empfangsbestätigungen, Empfangsanzeigen . . . . . . . . Seite 12

Nr. 1-64. Briefe im Warengeschäft.

Nr.

Seite

1-6 Kaffee . . . . . . . 22

7-13 Spielwaren . . . . . . 32

14-21 Strickwaren . . . . . . 40

22-32 Papier. . . . . . . . 52

33-40 Wein . . . . . . . . 68

41-44 Kunstblumen . . . . . 82

45-54 Leinwand. . . . . . 90

55-64 Erkundigung und Mahnung 102 a) Entable de relaciones, Preguntas acerca de los géneros y precios; $b$ ) Ofertas; $c$ ) Pedidos, ordénes; d) Acuse de recibo y ejecución de pedidos; e) Liquidación ó saldo de facturas; $f$ ) Acuses de recibo. Pág. 13

Correspondencia sobre mercancias. Café - $\cdot 0 \cdot 0$

Juguetes . . . . . . . . ร3

Géneros de punto . . . . . . . 41

Papel . . . . . . . . . . . 53

Vinos y aceites. . . . . . . 69

Flores artificiales . . . . . . . . 83

Telas . . . . . . . . . . . 91

Reclamaciones de crédito; cobranzas. 103

\section{Erläuterungen zum Bankgeschäft.}

\section{Nr. 65-94. Einzelne Bankgeschäfte. Operaciones bancarias.}

Eigengeschäfte; Kommissionsgeschäfte; Kassaverkehr; Verrechnungsverkehr; Giroverkehr; Kontokorrentverkehr. Seite 114

$$
\text { Briefe im Wechselverkehr. }
$$
Nr.

65-67 Diskontwechsel . . . . . 116

68-79 Kommissionswechsel . . . 122

80-85 Domizilwechsel . . . . . 136

86-94 Wechsel mit Notadresse . 142
En cuenta propia y en comisión; Al contado y en cuenta; Cuentas corrientes por efectosála vista; Cuenta corriente con intereses. P.115

\section{Correspondencia bancaria.}

Priginas

Descuento de efectos . . . . . 117

Giros por cuenta de tercero . . . 123

Domicilio de efectos . . . . . . 137

Pagos intervenidos. Protestos : 143 
Nr. 95-106. Kontokorrentverkehr.

a) Anträge, Angebote, Anerbieten, Offerten; b)Beantwortung des Antrags; c) Bankbedingungen; d) Bestätigung der Bedingungen; e) Aufträge: f) Rechnungsabschluß; g) Prüfungsbericht Seite 154

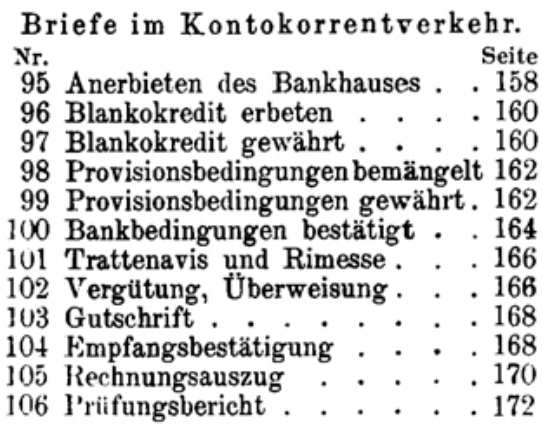

\section{Operaciones de cuenta corriente.}

a) Oferta de servicios; b) Entrada en transacciones; c) Estipulación de condiciones; $d$ ) Confirmación del convenio; $e$ ) Ordenes; f) Cierre $y$ extracto de cuentas; g) Confrontación . . . . Pág. 155

Cartas sobre cuentas corrientes. Páginas Oferta de servicios . . . . . . 159 Petición de crédito en blanco . . . 161 Concesión de crédito . . . . . . 161 Comisión suplementaria . . . . . 163 Estipulación de condiciones . . . . 163 Confirmación de lo estipulado. . . 165 Aviso de tratas; remesa . . . . 167 Giro á disposición. . . . . . . . 167 Acuse de recibo $\mathrm{y}$ abono en cuenta. 169 Acuse de conformidad . . . . . . 169 Ajuste y extracto de cuentas. . . 171 Examen $y$ conformidad . . . . . 173

\section{Erläuterungen zum Kommissionsgeschäft.}

Kommission und Kommissionär; Preisgrenze; Delkred ; Maklergebühr; Finkaufsrechnung; Verkaufsrechnung; Konsignationsfaktur
Comisión y consignación; Limitación; Del-crédere; Corretaje; Factura de compra; Factura de venta; Consignación.

Pág. 175

\section{Nr. 107-123. Briefe im Kommissionsgeschäft. Correspondencia sobre comisiónes.}

Einkaufskommission, Rauchwaren. $\mathrm{Nr} \quad$ Seite

107 Anerbieten des Kommissionärs. 180

108 Briefliches Anerbieten . . . 180

109 Annahme der Bedingungen . . 182

110 Zusicherung sorgfältiger $\mathrm{Be}$ dienung . . . . . . . . 184

111 Auftrag zu kaufen. . . . . 184

112 Versandanzeige; Marktbericht . 186

113 Originalfaktur . . . . . 186

114 Empfangsbestätigung; Ausstellungen . . . . . . . . 186

115 Auftrag sich zu erholen . . . 188

116 Trattenavis . . . . . . . 188

Verka ufskommission; Leder. Nr. Seite

117 Anerbieten des Kommissionärs . 190

118 Konsignationssendung . . . . . 192

119 Konsignationsfaktur . . . . 194

120 Prüfungsbericht; Provisionsermäßigung . . . . . 194

121 Verkaufsanzeige; Telegrammbestätigung. . . . . . 196

122 Verkaufsrechnung . . . . 198

123 Anschaffung durch Utberweisung 198
Compra de peletería en comisión.

Piginas

Oferta de servicios por circular . 181

Oferta detallada por escrito . . . 181

Aceptación de condiciones . . . . 183

Promesa de ejecución esmerada . . 185

Orden de compra . . . . . . . 185

Aviso de envío; reseña del mercado 187

Factura original . . . . . . . 187

Acuse de recibo, con quejas . . . 187

Invitación á disponer del importe .189

Aviso de trata. . . . . . . . 189

Venta de curtidos en comisión.

Páginas

Oferta del comisionista . . . . . 191

Consignación . . . . . . . . . . 193

Factura de consignación. . . . . 195

Examen del envio; rebaja de la comisión . . . . . . . . 195

Aviso de venta; confirmación del despacho . . . . . . . . . 197

Factura de venta . . . . . . . 199

Saldo mediante cheque . . . . . 199 


\section{Erläuterungen zum Speditionsgeschäft.}

Speditionsgeschäft und Spediteur; Nachnabme, Verzollung; Frachtführer, Verfrachter; Versicherung; Prämie, Police; Vorausbezahlung, Nachbezahlung; Tariffracht, Utbernahmsfracht . . Seite 200
Transportes y seguros; Medios de transporte; Gastos; Transportes según tarifa y á destajo; Seguros; Aduana; Reembolso . . . . . . . Pág. 201

\section{Nr. 124-152. Briefe im Speditionsgeschäft. Cartas sobre una expedición suelta.}

Weintransport von Cerbère nach Leipzig gegen Frachtübernahme. $\mathrm{Nr}$.

124 Anfrage wegen Transportübernahme . . . . . . 206

125 Angabe der Ưbernahmspreise . 206

126 Auftrag für Seetransport . . 208

127 Bitte um Absendung der Ware 208

128 Auftrag für den Zwischenspediteur . . . . . . . 210

129 Anzeige der Weiterbeförderung 210

130 Anmeldung zur Versicherung . 212

131 Auftrag für den Grenzspediteur 212

132 Anderung des Bestimmungsortes 214

133 Aufforderung zur Umladung . 214

134 Die Sendung ist bereits abgegangen . . . . . . . 216

135 Auftrag die Waren umzuladen. 216

136 Anzeige der erfolgten Umladung 218

137 Ausführungsanzeige . . . . 218

138 Abrechnung, Spesennota . . . 220

Warentransport in laufender Rechnung zwischen Leipzig und Cerbère. Nr. Seite 139 Anerbieten des Spediteurs . . 224

140 Bitte um billigere Frachtsätze. 226

141 Ermäßigung der Übernahmspreise 226

142 Die Ermäßigung ist ungenügend 228

143 Abermaliger Preisnachla $\beta$. . 228

144 Einsendung derKonkurrenzofferte 230

145 Zusicherung gleicherBedingungen 230

146 Übermittlung verschied.Aufträge 232

147 Aufforderung Güter abzuholen . 234

148 Versandanzeige . . . . . . 234

149 Versandinstruktionen . . . . 236

150 Anzeige einer Eilgutsendung . 236

151 Abrechnung; Bitte um Gutschrift 238

152 Empfangsanzeige; Gutschrift . 240
Transporte á destajode una partida de vino, de Cerbère á Leipzig.

Pregunta de condiciones de transPáginas porte . . . . . . . . . . 207 Oferta á destajo . . . . . . . . 207

Oferta de transporte por mar y por río 209

Expedición de la mercancía . . . 209

Aviso del envío al agente intermediario . . . . . . . . 211 Aviso de expedición al destinatario . 211 Aviso de reexpedición á los comitentes 213 Aviso de reexpedición al destinatario 213 Encargo del seguro . . . . . . 215

Aviso á la casa naviera . . . . . 215

Acuse de recibo . . . . . . . 217

Orden de trasbordo . . . . . . . 217

Aviso del trasbordo efectuado . . . 219

Carta con la nota de gastos . . . 219

Nota de gastos. . . . . . . . 221

Transportes en cuenta corriente entre Portbou-Cerbère y Leipzig. Páginas

Oferta del agente expedidor . . . 225

Petición de precios reducidos . . . 227

Rebaja de la tarifa . . . . . . 227

Insuficiencia de la reducción . . . 229

Nueva rebaja . . . . . . . . . 229

Envio de la oferta de un competidor 231 Aceptación de las mismas condiciones 231 Transmisión de varias órdenes . . 233

Invitación á retirar envios . . . . 235

Aviso de expedición . . . . . . . 235

Instrucciones sobre el transporte. . 237

Aviso de envío á gran velocidad. . 237

Ajuste de cuentas; asientos . . . 239

Acuse de recibo; abono en cuenta . 241

\section{Umwandlung der Brieftexte.}

$\mathrm{Nr}$

1 - 64 Warengeschäfte

Tráfico de mercancías . . . . . 242

65-106 Bankgeschäfte . . . . . . Operaciones bancarias . . . . . 248

107-123 Komissionsgeschäfte . . . . Comisión y consignación . . . . 252

124-152 Speditionsgeschäfte . . . . Transportes y seguros . . . . . . 259 


\section{Aufgaben für anzufertigende Briefe.}

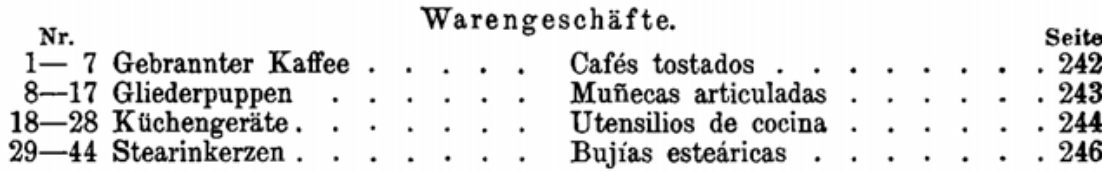

Bankgeschäfte.

45-46 Wechsel zur Annahme . . . Aceptación de efectos . . . . . 248

47-49 Wechsel zurBesórg. der Annahme Encargo de hacer aceptar efectos . 248

50-52 Wechsel zur Diskontierung. . Efectos á descontar . . . . . . 248

53-56 Rimessen für eigene Rechnung Remesas por cuenta propia . . . 249

57-62 Rimessen für fremde Rechnung Remesas por cuenta agena . . . . 249

63-69 Tratten für fremde Rechnung. Tratas por cuenta agena . . . . 250

70-77 Wechsel zur Domizilierung . . Efectos á domiciliar . . . . . . 251

Kommissionsgeschäfte.

78- 88 Einkauf von Borsten und Haarpinselmaterial . . . . . Compra de sedas y pieles . . . . 252

89-111 Verkauf von Kammzug. . . Venta de géneros peinados . . . 254

Speditionsgeschäfte.

112-122 Transportübernahme . . . . Transportes á destajo . . . . . 259

\section{Anhang.}

Im Handelsbrief vorkommende Abkürzungen . . . . . . . . . . 261

Abreviaturas mercantiles. . . . . . . . . . . . . . . . . 261

Formulare.

Einfache Quittung . . . . . . Recibo talonario . . . . . . 266

Doppelquittung . . . . . . . . . Duplicado del recibo precedente . 267

Eigenwechsel . . . . . . . . . . Pagaré. . . . . . . . . . 268

Weißer Scheck . . . . . . . . . Cheque . . , . . . . . . . 269

Gezogener Wechsel mit Akzept . . . Letra aceptada. . . . . . . . 270

Domizilwechsel . . . . . . . . . Efecto domiciliado . . . . . . . 272

Rechnung. . . . . . . . . . Factura . . . . . . . . 274 